\title{
The impact of taxane-based preoperative chemotherapy in gastroesophageal signet ring cell adenocarcinomas
}

\author{
Stefano Kim ${ }^{1,2,3^{*}}$, Frederic Fiteni ${ }^{1,4}$, Sophie Paget-Bailly ${ }^{4}$, François Ghiringhelli ${ }^{5}$, Zaher Lakkis ${ }^{6}$, Marine Jary ${ }^{1,3}$, \\ Francine Fein ${ }^{7}$, Franck Bonnetain ${ }^{4,8}$, Christophe Mariette ${ }^{9}$ and Christophe Borg ${ }^{1,2,3}$
}

\begin{abstract}
The benefit of preoperative chemotherapy in resectable gastroesophageal adenocarcinomas was not observed in signet ring cell subtype. However, the potential interest of taxane-based preoperative chemotherapy on this subtype is still an unresolved issue. Nineteen patients with localized signet ring cell adenocarcinomas received taxane-based regimens, and 17 patients underwent surgery. Complete resection was achieved in $80 \%$, and median overall survival was 40.8 months (95\% confidence interval (Cl), 20.2-not reached). Even though one patient achieved a complete pathological response, seven patients had an upstaging of their tumors at surgery. The potential benefits of taxane-based chemotherapy seem to be limited to a reduced number of patients.
\end{abstract}

Keywords: Signet ring cell, Gastroesophageal cancer, Gastric cancer, Preoperative, Neoadjuvant, Taxane, Docetaxel, Paclitaxel

\section{Findings}

\section{Background}

Signet ring cell (SRC) adenocarcinoma is a particular histological subtype of gastroesophageal adenocarcinomas (GEA) displaying a worse prognosis [1]. Even though the perioperative chemotherapy (PCT) in resectable GEA demonstrated a significant benefit in terms of overall survival (OS) compared to surgery alone [2, 3], this benefit seems to be limited to non-SRC histology [4]. This observation prompted physicians to perform surgery without preoperative chemotherapy in SRC GEA patients with a resectable disease.

Taxanes are potent microtubule-stabilizing agents with demonstrated antitumor activity in advanced GEA and with encouraging results in resectable GEA, as reported in several phase II trials [5-10]. The potential interest of taxane-based PCT on SRC GEA is still an unresolved issue.

\footnotetext{
* Correspondence: chkim@chu-besancon.fr

${ }^{1}$ Department of Medical Oncology, University Hospital of Besancon, 3 Boulevard Alexander Fleming, Besancon F-25030, France

${ }^{2}$ Clinical Investigational Centre, CIC-1431, University Hospital of Besançon, Besançon, France

Full list of author information is available at the end of the article
}

\section{Results}

Between January 2005 and December 2012, 19 patients with localized SRC GEA received taxane-based PCT from six French hospitals. (Additional file 1) Patients' median age was 64 years (range, $41-81$ years). The majority of tumors $(58 \%)$ were located in the stomach and were predominantly stage III (42\%) and II (42\%) (Table 1).

Most frequent neoadjuvant chemotherapy regimens were DCF regimen in seven patients (37\%), as described in TAX-325 trial, and PET regimen in other seven patients $(37 \%)$ as previously published $[5,10]$. Three patients $(16 \%)$ received TFOX regimen (Table 1$)$.

Seventeen patients $(89 \%)$ underwent surgery. One patient presented an unexpected death (cardiac failure) after three DCF cycles and before surgery, and another patient refused surgery after eight PET cycles. Total gastrectomy was performed in eight patients (47 \%) and esophagogastrectomy via abdominal and right thoracic approaches (Lewis-Santi) in seven patients (41\%). Postoperative adverse events were observed in three patients with favorable recovery (Table 1 ).

All 17 patients who underwent surgery had a curativeintent resection. Pathological information about surgical margins was available in 15 patients, and the pathological 
Table 1 Patient and tumors' characteristics

\begin{tabular}{|c|c|c|}
\hline \multicolumn{3}{|c|}{ Patient and tumors' characteristics before surgery } \\
\hline & $N=1$ & \\
\hline Age, years (range) & 64 & $41-81$ \\
\hline Gender & No & $\%$ \\
\hline Male & 14 & 74 \\
\hline Female & 5 & 26 \\
\hline ECOG-PS & No & $\%$ \\
\hline 0 & 11 & 58 \\
\hline 1 & 5 & 26 \\
\hline 2 & 3 & 16 \\
\hline Location of tumor & No & $\%$ \\
\hline Distal esophagus or GEJ & 8 & 42 \\
\hline Stomach & 11 & 58 \\
\hline Clinical TNM stage & No & $\%$ \\
\hline Stage I & 3 & 16 \\
\hline Stage ॥ & 8 & 42 \\
\hline Stage III & 8 & 42 \\
\hline Stage IV & 0 & 0 \\
\hline Neoadjuvant chemotherapy & No & $\%$ \\
\hline DCF & 7 & 37 \\
\hline PET & 7 & 37 \\
\hline TFOX & 3 & 16 \\
\hline Docetaxel-Cisplatin & 1 & 5 \\
\hline Cisplatin-Paclitaxel-Doxorubicin & 1 & 5 \\
\hline
\end{tabular}

Surgery and postoperative variables

$\begin{array}{lll}\text { Type of surgery, No (\%) } & \text { No } & \% \\ \text { Total gastrectomy } & 8 & 47 \\ \text { Subtotal gastrectomy } & 2 & 12 \\ \text { Lewis-Santi esophagectomy* } & 7 & 41 \\ \text { Lymphadenectomy extend } & \text { No } & \% \\ \text { D1 } & 4 & 31 \\ \text { Modified D2 } & 6 & 46 \\ \text { D2 } & 3 & 23 \\ \text { Missing } & 4 & - \\ \text { Resection } & \text { No } & \% \\ \text { R0 } & 12 & 80 \\ \text { R1 } & 3 & 20 \\ \text { R2 } & 0 & 0 \\ \text { Missing } & 2 & - \\ \text { Pathological tumor classification } & \text { No } & \% \\ \text { PT0 } & 1 & 6 \\ \text { pT1 } & 2 & 13 \\ \text { PT2 } & 3 & 19 \\ \text { pT3 } & 5 & 31\end{array}$

Table 1 Patient and tumors' characteristics (Continued)

\begin{tabular}{lll}
\hline pT4 & 5 & 31 \\
Missing & 1 & - \\
Pathologic nodal classification & No & $\%$ \\
pN0 & 2 & 13 \\
pN1 & 6 & 38 \\
pN2 & 3 & 19 \\
pN3 & 5 & 31 \\
Missing & 1 & - \\
Pathologic metastatic stage & No & $\%$ \\
pM0 & 15 & 88 \\
pM1 & 2 & 12 \\
Adjuvant treatment & No & $\%$ \\
DCF & 3 & 18 \\
Docetaxel-Cisplatin & 1 & 6 \\
TFOX & 1 & 6 \\
mFOLFOX6 & 6 & 35 \\
EOX & 2 & 12 \\
Chemoradiotherapy & 2 & 12 \\
No adjuvant treatment & 2 & 12
\end{tabular}

ECOG-PS Eastern Cooperative Oncology Group-performance status, GEJ gastroesophageal junction, DCF 3 cycles of docetaxel $\left(75 \mathrm{mg} / \mathrm{m}^{2} \mathrm{~d} 1\right)$, cisplatin $\left(75 \mathrm{mg} / \mathrm{m}^{2} \mathrm{~d} 1\right)$, and 5 -fluorouracil $\left(750 \mathrm{mg} / \mathrm{m}^{2} / \mathrm{d}\right.$ on continuous perfusion on days 1 to 5), every 3 weeks, PET 8 cycles of cisplatin $\left(30 \mathrm{mg} / \mathrm{m}^{2} \mathrm{~d} 1\right)$, epirubicin $\left(50 \mathrm{mg} / \mathrm{m}^{2} \mathrm{~d} 1\right)$, and paclitaxel $\left(80 \mathrm{mg} / \mathrm{m}^{2} \mathrm{~d} 1\right)$, every week, TFOX docetaxel $\left(50 \mathrm{mg} / \mathrm{m}^{2}\right)$, oxaliplatin $\left(85 \mathrm{mg} / \mathrm{m}^{2}\right)$, leucovorin $\left(400 \mathrm{mg} / \mathrm{m}^{2}\right)$ and $5 \mathrm{FU}$ continuous infusion $48 \mathrm{~h}\left(2400 \mathrm{mg} / \mathrm{m}^{2}\right), S$ surgery alone, D1 lymphadenectomy limited to regional lymph nodes, modified D2 extended lymph node dissection without pancreatectomy and splenectomy, D2 extended lymph node dissection with pancreatectomy and/or splenectomy, mFOLFOX6 oxaliplatin, leucovorin, $5 \mathrm{FU}$ bolus and 5FU continuous infusion 48 h, EOX epirubicin, oxaliplatin and capecitabine

*Oesophagectomy via abdominal and right thoracic approaches

complete resection (R0) was achieved in 12 patients (80\%). One patient presented a complete pathological response (pCR). This patient had a T2 disease with lymph node enlargement at diagnosis. In seven patients, more advanced disease was found at surgery compared to initial staging. Two patients presented intraoperative peritoneal metastases, and five patients had T4 disease (Table 1).

After a median follow up of 26.2 months (15.5-71.5), eight patients died and nine patients progressed. The median OS was 40.8 months (95\% confidence interval (CI), 20.2-not reached), and the median PFS was 36.8 months (95\% CI, 10.0-not reached). Five-year OS and PFS rates were $30.4 \%$ and $29.3 \%$, respectively (Fig. 1).

\section{Conclusion}

Even though our study has obvious limitations as a retrospective analysis and regarding the limited number of patients, this is the largest cohort of SRC GEA patients 


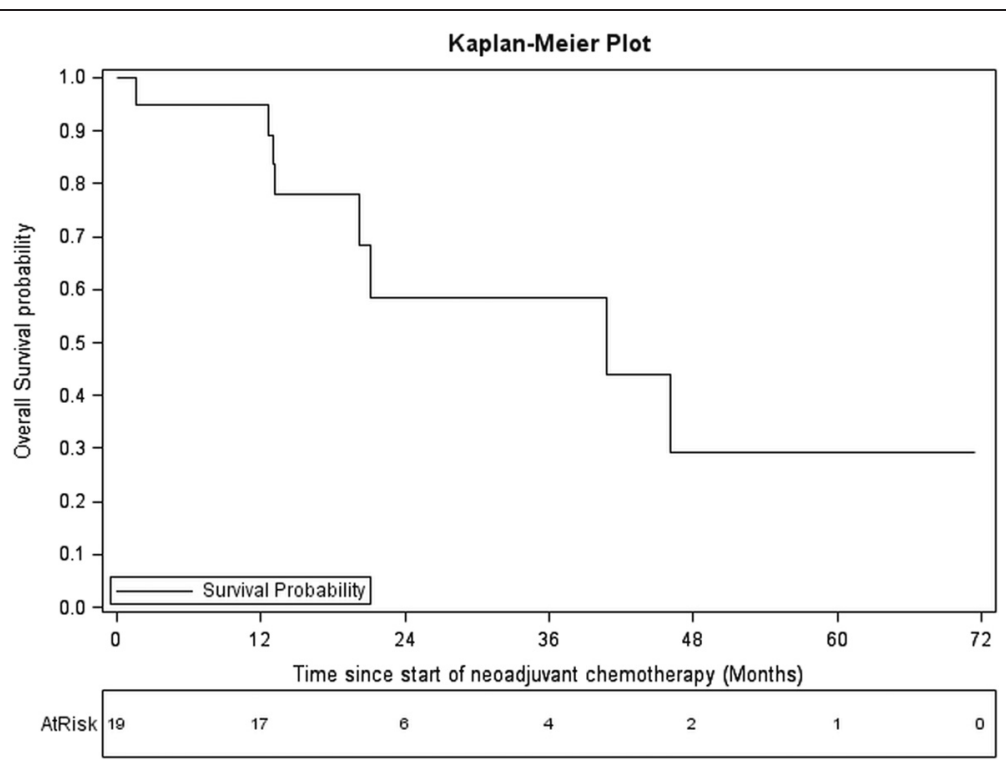

Fig. 1 OS estimated using Kaplan Meier method

treated with preoperative taxane-based chemotherapy published so far. The potential benefits of taxane-based PCT seem to be limited to a reduced number of patients with SRC GEA. The high number of patients with pathological upstaging reinforces the results of Messager et al. and the recommendation to perform front line surgery in resectable SRC GEA without PCT [4]. Future efforts should be focused on developing predictive biomarkers to identify SRC GEA patients potentially sensitive to taxanes.

\section{Future perspectives}

Targeted agents have shown promising results in advanced GEA. [11] Among them, trastuzumab (in HER2 positive patients) and ramucirumab have been approved in advanced GEA. However, most SRC GEAs are HER2 negative, and ramucirumab, an antiangiogenic mAb selectively targeting VEGFR2, will hardly be developed in perioperative setting due to negative experience of bevacizumab in gastrointestinal adenocarcinomas [12, 13]. Among novel molecules in development in GEA, checkpoint inhibitors are probably the most promising. Pembrolizumab, an antiPD1 mAb was administered as monotherapy in 39 GEA patients with PD-L1 expression. Most patients have received $\geq 2$ prior chemotherapies. An encouraging overall response rate of $22 \%$ and the 6 -month OS rate of $69 \%$ were observed [14]. The expression of PD-L1 in SRC GEA is present in about $23 \%$, and a growing body of evidence suggests that taxane induces immunogenic cell death sustaining the potential interest to combine taxane and antiPD1 in clinical trials including SRC GEA patients $[15,16]$.
Pembrolizumab and other checkpoint inhibitors should be evaluated in prospective preoperative trials in GEA patients including SRC histology, probably in association with taxane-based chemotherapy. Future exhaustive molecular analysis in SRC GEA is needed to find targets for novel molecules in this chemorefractory disease.

\section{Additional file}

Additional file 1: Methods.

\section{Abbreviations}

SRC: Signet ring cell; GEA: Gastroesophageal adenocarcinomas; PCT: Preoperative chemotherapy; OS: Overall survival; DCF: 3 cycles of docetaxel, cisplatin, and 5-fluorouracil, every 3 weeks; PET: 8 cycles cisplatin, epirubicin, paclitaxel, weekly; TFOX: 6 cycles of docetaxel, oxaliplatin, leucovorin, and 5FU, every 2 weeks; R0: Complete resection; pCR: Pathological complete response; PFS: Progression free survival; HER2: Human epidermal growth factor receptor 2; mAb: Monoclonal antibody; VEGFR2: Vascular endothelial growth factor receptor 2; PD1: Programmed cell death protein 1; PD-L1: Programmed cell death-ligand 1.

\section{Competing interest}

The authors declare that they have no competing interests.

\section{Authors' contributions}

SK conceived the study, participated in its design, acquisition and interpretation of data, and coordination, and helped to draft the manuscript. FFi participated in study design, acquisition of data and statistical analysis, and helped to draft the manuscript. SPB participated in statistical analysis and helped to draft manuscript. FG participated in acquisition. ZL participated in acquisition of data. MJ participated in acquisition of data. FFe participated in acquisition of data. FB participated in its design and statistical analysis and helped to draft the manuscript. CM participated in acquisition and interpretation of data and helped to draft the manuscript. CB conceived the study, participated in its design and interpretation of data, and helped to draft the manuscript. All authors read and approved the final manuscript. 


\section{Acknowledgments}

The authors would like to thank Guadalupe Tizon for English writing assistance.

\section{Author details}

${ }^{1}$ Department of Medical Oncology, University Hospital of Besancon, 3 Boulevard Alexander Fleming, Besancon F-25030, France. ${ }^{2}$ Clinical Investigational Centre, CIC-1431, University Hospital of Besançon, Besançon, France. ${ }^{3}$ INSERM, Unit 1098, University of Franche-Comté, Besançon, France. ${ }^{4}$ Methodology and Quality of Life in Oncology Unit, University Hospital of Besançon, Besançon, France. ${ }^{5}$ Department of Oncology, Georges-Francois Leclerc Cancer Center, Dijon, France. ${ }^{6}$ Department of Digestive Surgery and Liver Transplantation, University Hospital of Besançon, Besançon, France. ${ }^{7}$ Department of Gastroenterology, University Hospital of Besançon, Besançon, France. ${ }^{8}$ EA 3181 University of Franche-Comté, Besançon, Besançon, France. ${ }^{9}$ Department of Digestive Surgery, Lille University Hospital, Lille, France.

Received: 22 April 2015 Accepted: 6 May 2015

Published online: 15 May 2015

\section{References}

1. Piessen $G$, Messager $M$, Leteurtre $E_{1}$ Jean-Pierre $T$, Mariette $C$. Signet ring cell histology is an independent predictor of poor prognosis in gastric adenocarcinoma regardless of tumoral clinical presentation. Ann Surg. 2009:250:878-87.

2. Cunningham D, Allum WH, Stenning SP, Thompson JN, van de Velde $\mathrm{CJH}$, Nicolson $\mathrm{M}$, et al. Perioperative chemotherapy versus surgery alone for resectable gastroesophageal cancer. N Engl J Med. 2006;355:11-20.

3. Ychou M, Boige V, Pignon JP, Conroy T, Bouché O, Lebreton G, et al Perioperative chemotherapy compared with surgery alone for resectable gastroesophageal adenocarcinoma: an FNCLCC and FFCD multicenter phase III trial. J Clin Oncol. 2011;29:1715-21.

4. Messager M, Lefevre JH, Pichot-Delahaye V, Souadka A, Piessen G, Mariette C, et al. The impact of perioperative chemotherapy on survival in patients with gastric signet ring cell adenocarcinoma. Ann Surg. 2011:254:684-93.

5. Jary $M$, Ghiringhelli $F$, Jacquin $M$, Fein F, Nguyen $T$, Cleau $D$, et al. Phase II multicentre study of efficacy and feasibility of dose-intensified preoperative weekly cisplatin, epirubicin, and paclitaxel (PET) in resectable gastroesophageal cancer. Cancer Chemother Pharmacol. 2014;74:141-50.

6. Ferri LE, Ades S, Alcindor T, Chasen M, Marcus V, Hickeson M, et al. Perioperative docetaxel, cisplatin, and 5-fluorouracil (DCF) for locally advanced esophageal and gastric adenocarcinoma: a multicenter phase II trial. Ann Oncol. 2012;23:1512-7.

7. Thuss-Patience PC, Hofheinz RD, Arnold D, Florschütz A, Daum S, Kretzschmar A, et al. Perioperative chemotherapy with docetaxel, cisplatin and capecitabine (DCX) in gastro-oesophageal adenocarcinoma: a phase II study of the Arbeitsgemeinschaft Internistische Onkologie (AIO). Ann Oncol. 2012;23:2827-34

8. Park I, Ryu M-H, Choi YH, Kang HJ, Yook JH, Park YS, et al. A phase II study of neoadjuvant docetaxel, oxaliplatin, and S-1 (DOS) chemotherapy followed by surgery and adjuvant S-1 chemotherapy in potentially resectable gastric or gastroesophageal junction adenocarcinoma. Cancer Chemother Pharmacol. 2013;72:815-23.

9. Schulz C, Kullmann F, Kunzmann V, Fuchs M, Geissler M, Vehling-Kaiser U, et al. NeoFLOT: multicenter phase II study of perioperative chemotherapy in resectable adenocarcinoma of the gastroesophageal junction or gastric adenocarcinoma-Very good response predominantly in patients with intestinal type tumors. Int J Cancer. 2014. doi:10.1002/ijc.29403.

10. Van Cutsem E, Moiseyenko VM, Tjulandin S, Majlis A, Constenla M, Boni C, et al. Phase III study of docetaxel and cisplatin plus fluorouracil compared with cisplatin and fluorouracil as first-line therapy for advanced gastric cancer: a report of the V325 Study Group. J Clin Oncol. 2006;24:4991-7.

11. Liu L, Wu N, Li J. Novel targeted agents for gastric cancer. J Hematol Oncol. 2012;5:31.

12. Kim KC, Koh YW, Chang H-M, Kim TH, Yook JH, Kim BS, et al. Evaluation of HER2 protein expression in gastric carcinomas: comparative analysis of 1,414 cases of whole-tissue sections and 595 cases of tissue microarrays. Ann Surg Oncol. 2011;18:2833-40.

13. Idelevich E, Kashtan H, Klein Y, Buevich V, Baruch NB, Dinerman M, et al. Prospective phase II study of neoadjuvant therapy with cisplatin, 5-FU, and bevacizumab for locally advanced resectable esophageal cancer. Onkologie. 2012;35:427-31.

14. Muro K, Bang Y-J, Shankaran V, Geva R, Thomas DV, Gupta S, et al. Relationship between PD-L1 expression and clinical outcomes in patients with advanced gastric cancer treated with the anti-PD-1 monoclonal antibody pembrolizumab in KEYNOTE-012. J Clin Oncol. 2015;33 Suppl 3:abstr 3.

15. Qing Y, Li Q, Ren T, Xia W, Peng Y, Liu GL, et al. Upregulation of PD-L1 and APE1 is associated with tumorigenesis and poor prognosis of gastric cancer. DDDT. 2015;9:901-9.

16. Senovilla L, Vitale I, Martins I, Tailler M, Pailleret C, Michaud M, et al. An immunosurveillance mechanism controls cancer cell ploidy. Science. 2012;337:1678-84

\section{Submit your next manuscript to BioMed Central and take full advantage of:}

- Convenient online submission

- Thorough peer review

- No space constraints or color figure charges

- Immediate publication on acceptance

- Inclusion in PubMed, CAS, Scopus and Google Scholar

- Research which is freely available for redistribution 